\title{
Curative Radiotherapy Outcomes in Elderly Bladder Cancer Patients: A Single-Center Experiences
}

\author{
(1) Berrin INANÇ, (1) Özlem MERMUT \\ Department of Radiation Oncology, Istanbul Training and Research Hospital, Istanbul-Turkey
}

\begin{abstract}
OBJECTIVE
In this retrospective research, it was aimed to evaluate results of radiotherapy (RT) in elderly bladder cancer patients.

\section{METHODS}

A total of 47 patients who receiving RT or chemoradiotherapy treatment for bladder cancer in elderly patient ( $>70$ years) were included in the study.

\section{RESULTS}

In total 47 patients, 4 patients (8.5\%) had Stage I, 38 patients (80.8\%) had Stage II, and 5 patients (10.6\%) had Stage III bladder cancer. About $76.9 \%$ of patients had invasive urothelial, $3.8 \%$ of patients had squamous and micropapillary carcinoma, and $19.2 \%$ of had other (adenocarcinoma) histopathological type. Gender, age, family cancer history, hematuria, smoking, bladder carcinoma type, Charlson CoMorbidity Index, RT dose, concurrent chemoradiotherapy, metastasis side, acute and late toxicity, and follow-up duration of patients showed insignificant differences according to stage ( $p>0.05)$. We found that overall survival and disease-free survival (DFS) were statistically significant according to the stages $(\mathrm{p}<0.05)$. DFS for Karnofsky Performance Status (KPS) $>70$ group $(25.97 \pm 19.06)$ was higher than KPS $<70$ group $(2.37 \pm 1.53)$ with statistically significant difference $(\mathrm{p}<0.05)$.
\end{abstract}

\section{CONCLUSION}

Curative RT and chemoradiotherapy can be safe regimen for older ( $>70$ year) patients with bladder cancer. Nonetheless, KPS and geriatric assessments tools should be consideration before RT and chemoradiotherapy administration.

Keywords: Aged; bladder neoplasms; radiotherapy; stage. Copyright $\odot$ 2021, Turkish Society for Radiation Oncology

\section{Introduction}

Bladder cancer is a type of cancer usually seen in older adults. Most of these patients are 65 years and older. The median age at diagnosis is 72 years.[1] Approximately $70 \%$ of bladder cancers are muscle non-invasive while $25-30 \%$ of bladder cancer are muscle invasive bladder cancer.[2] While frequent recurrences are seen in non- muscle-invasive bladder cancer (NMIBC) patients, intravesical treatments are insufficient for high-grade tumor (T1, high grade). In these patients and muscleinvasive bladder cancer (MIBC) patients although cystectomy is the standard treatment, it may not be possible in elderly patients because of comorbidity diseases, general condition, and surgery complication. Maximal transurethral resection (TUR) followed by concurrent 
chemotherapy and radiation (CRT) is similar effective to radical surgery. $[3,4]$ Most of the time, alone radiotherapy (RT) is applied after TUR in the elderly ( $>80$ years). These non-surgical treatments, called bladder-sparing treatment, are very important in the elderly patient group. The most important problem of bladder sparing treatment in elderly patients is treatment-related toxicities. Therefore, when deciding on bladder sparing treatments in elderly patients, advantages and disadvantages of these treatments should be take into consideration.

In this study, we aimed to investigate outcome of elderly patients with MIBC and NMIBC who taken curative $\mathrm{RT}$ and CRT after TUR.

\section{Materials and Methods}

In this retrospective study, we evaluated 47 patients over 70 years of age who were diagnosed with invasive bladder cancer after TUR, who were not eligible for radical surgery or who did not want to undergo radical surgery (T1 and high grade patients) and who were referred to Istanbul Training and Research Hospital Department of Radiation Oncology between 2011 and 2018. The study was approved by the local ethics committee of the University of Health Science, Istanbul Training and Research Hospital, Turkey, Human Research Ethics Committee (approval number: H: 2019-1859) according to Helsinki declaration, and informed consent was obtained from all patients after thorough explanation of the study. While all related laboratory and pathology results were obtained from hospital data, data related to treatment follow-up were obtained from clinical files. Patients had distant metastases, or received palliative dose RT were excluded from the study.

The general status of the patients was evaluated by Karnofsky Performance Status (KPS) Scores range from 0 to $100(<70$ and $\geq 70)$. The status of comorbidities was determined using the Charlson Comorbidity Index.[5]

\section{RT and Chemoradiotherapy Data}

All patients received maximal TUR. All patients received external beam RT in 1.8-2.0 Gy daily fractions with $18 \mathrm{MV}$ photon beams, 5 days a week. Pelvic lymph nodes were sometimes included and applied to the bladder or tumor to 65 Gy after 40-45 Gy. Radiation treatment was carried out using field-in field intensitymodulated radiation treatment and 4 -field box three-dimension conformal technique. The clinical target volume (CTV) included gross tumor volume and covered any direct extension of the tumor. The planning treatment volume was the CTV with addition of a
1-1.5 $\mathrm{cm}$ margin. Almost all patients received a phase 2 boost to the tumor bed.

Chemotherapy protocol Cisplatin $35 \mathrm{mg} / \mathrm{m}^{2}$, weekly to be administered by the Medical Oncology Clinic.

\section{Treatment Toxicity and Follow-up}

Treatment toxicity was evaluated with the Common Terminology Criteria for Adverse Events version 4.0.[6] During RT, patients were evaluated at least once a week with a clinical examination, and their blood counts and biochemistries were analyzed. The treatment responses were assessed using cystoscopy. Subsequent controls included physical examinations and cystoscopy and radiological imaging every 3 months. Follow-ups were conducted every 3 months for the first 2 years and every 6 months for years 3 through 5. During the followup period, a magnetic resonance imaging examination was requested in patients with suspected local or regional recurrence.

\section{Statistical Analysis}

Nominal and ordinal data were described with frequency analysis, whereas scale parameters were described with mean and standard deviations. Chi-square with likelihood ratio was used for differences between nominal and ordinal parameters. KolmogorovSmirnov test was used for normality of scale parameters. For normally distributed parameters, one-way ANOVA Test was used, and Kruskal-Wallis Test was used for non-normally distributed parameters. Kaplan-Meier analysis was used for disease-free survival (DFS) analysis for different patient groups. All analyses were performed at $95 \%$ confidence level with 0.05 significance level at SPSS 17.0 for windows program.

\section{Results}

Some baseline characteristics of patients and treatment features according to stage groups are given in Table 1. About $18.4 \%$ of Stage II patients, $20 \%$ of Stage III patients were females, and in total, $19.2 \%$ of patients were females with insignificant difference ( $p>0.05)$. Mean age was the highest in Stage III patients. Family CA history rate was $25.0 \%$ in Stage I, 10.5\% in Stage II, and 20.0\% in Stage III patients. About $25.0 \%$ of Stage I patients, $68.4 \%$ of Stage II patients, $80.0 \%$ of Stage III patients had hematuria. $25.0 \%$ of Stage I patients, $50.0 \%$ of Stage II patients, $20.0 \%$ of Stage III patients were smokers. 50.0\% of Stage I patients, $78.9 \%$ of Stage II patients, and $80.0 \%$ of Stage III patients had invasive urothelial type. About $50.0 \%$ of Stage I patients, $15.8 \%$ of Stage II patients, and 
Table 1 Patients characteristics and treatment features of patients according to stage groups

\begin{tabular}{|c|c|c|c|c|c|}
\hline Parameter & Stage I $(n=4)$ & Stage II ( $n=38)$ & Stage III $(n=5)$ & Total & $\mathbf{p}$ \\
\hline \multicolumn{6}{|l|}{ Gender, n (\%) } \\
\hline Female & - & $6(18.4)$ & $1(20.0)$ & $7(19.2)$ & $0.312^{\mathrm{a}}$ \\
\hline Male & $4(100.0)$ & - & - & $42(80.8)$ & \\
\hline Age, Mean \pm SD & $73.50 \pm 1.73$ & $75.42 \pm 6.12$ & $78.40 \pm 3.85$ & $75.54 \pm 5.63$ & $0.164^{b}$ \\
\hline Family CA history, n (\%) & $1(25.0)$ & $4(10.5)$ & $1(20)$ & $6(11.5)$ & $0.322^{\mathrm{a}}$ \\
\hline \multicolumn{6}{|l|}{ First complaint } \\
\hline Hematuria & $1(25.0)$ & $26(68.4)$ & $4(80.0)$ & $31(76.5)$ & $0.277^{\mathrm{a}}$ \\
\hline Clottet hematuria & $3(75.0)$ & $12(31.6)$ & $1(20.0)$ & $16(34.0)$ & \\
\hline \multicolumn{6}{|l|}{ Smoking n (\%) } \\
\hline None & $2(50.0)$ & $7(18.4)$ & $1(20.0)$ & $10(21.2)$ & \\
\hline Smoker & $1(25.0)$ & $19(50.0)$ & $1(20.0)$ & $21(44.6)$ & $0.480^{\mathrm{a}}$ \\
\hline Ex-smoker & $1(25.0)$ & $12(31.6)$ & $3(60.0)$ & $16(34.0)$ & \\
\hline \multicolumn{6}{|l|}{ Type, n (\%) } \\
\hline Invasive urothelial & $2(50.0)$ & $30(78.9)$ & $4(80.0)$ & $36(76.9)$ & $0.656^{\mathrm{a}}$ \\
\hline Squamos+micropap. & - & $2(5.3)$ & - & $2(0.4)$ & \\
\hline Other & $2(50.0)$ & $6(15.8)$ & $1(20.0)$ & $9(19.2)$ & \\
\hline \multicolumn{6}{|l|}{ KPS, n (\%) } \\
\hline$>70$ & $4(100.0)$ & $24(63.2)$ & $3(60.0)$ & $31(65.9)$ & $0.177^{\mathrm{a}}$ \\
\hline$<70$ & - & $14(36.8)$ & $2(40.0)$ & $16(34.0)$ & \\
\hline \multicolumn{6}{|l|}{ Charlson Comorbidity Criteria } \\
\hline $0-1$ & - & - & - & - & \\
\hline $2-3$ & $1(25.0)$ & $22(57.9)$ & $5(100.0)$ & $32(68.0)$ & $0.110^{\mathrm{a}}$ \\
\hline 4-5 & $3(75.0)$ & $12(31.5)$ & - & $15(24.0)$ & \\
\hline 6-7 & - & $4(10.6)$ & - & $4(8.0)$ & \\
\hline \multicolumn{6}{|l|}{ RT dose (Gy) } \\
\hline 45 & - & $2(5.2)$ & - & $2(4.2)$ & $0.266^{\mathrm{a}}$ \\
\hline 60 & $4(100.0)$ & $35(92.1)$ & $3(60.0)$ & $42(88.6)$ & \\
\hline 64 & - & $1(2.7)$ & $2(40.0)$ & $3(6.3)$ & \\
\hline \multicolumn{6}{|l|}{ RT break } \\
\hline Yes & - & $6(15.8)$ & $1(20.0)$ & $7(14.8)$ & $0.358^{a}$ \\
\hline No & $4(100.0)$ & $32(84.2)$ & $4(80.0)$ & $40(85.1)$ & \\
\hline Concurrent cisplatin & $2(50.0)$ & $18(47.4)$ & $3(60.0)$ & $23(50.0)$ & $0.726^{a}$ \\
\hline \multicolumn{6}{|l|}{ Metastasis, n (\%) } \\
\hline None & $4(100.0)$ & $32(84.2)$ & $2(40.0)$ & $38(80.8)$ & \\
\hline Bone & - & $1(2.6)$ & $2(40.0)$ & $3(5.8)$ & \\
\hline Lung & - & $1(2.6)$ & $1(20.0)$ & $2(3.8)$ & $0.455^{\mathrm{a}}$ \\
\hline Liver & - & $3(7.9)$ & - & $3(5.8)$ & \\
\hline Brain & - & $1(2.6)$ & - & $1(1.9)$ & \\
\hline Exitus, n (\%) & $1(25.0)$ & $28(73.7)$ & $5(100.0)$ & $34(72.3)$ & $0.066 a$ \\
\hline Follow-up, (month) Mean \pm SD & $33.00 \pm 14.7$ & $31.95 \pm 23$ & $11.60 \pm 5.2$ & $29.40 \pm 23.3$ & $0.231 \mathrm{c}$ \\
\hline \multicolumn{6}{|l|}{ Acute Toxicity, n (\%) } \\
\hline \multicolumn{6}{|l|}{ Diarrhea } \\
\hline Grade 1 & - & - & - & - & \\
\hline Grade 2 & $2(50.0)$ & $4(10.5)$ & - & $6(12.7)$ & $0.079 a$ \\
\hline \multicolumn{6}{|l|}{ Urinary Frequency, n (\%) } \\
\hline Grade 1 & $3(75.0)$ & $34(89.5)$ & $4(80.0)$ & $41(87.2)$ & \\
\hline Grade 2 & $1(25.0)$ & $4(10.5)$ & $1(20.0)$ & $6(12.7)$ & $0.525^{\mathrm{a}}$ \\
\hline \multicolumn{6}{|l|}{ Hematologic, n (\%) } \\
\hline Grade 1 & $2(40.0)$ & $22(57.8)$ & $1(20.0)$ & $25(48.0)$ & $0.084^{\mathrm{a}}$ \\
\hline \multicolumn{6}{|l|}{ Late toxicity, n (\%) } \\
\hline \multicolumn{6}{|l|}{ Cysitis } \\
\hline None & $1(25.0)$ & $14(36.8)$ & $1(20.0)$ & $16(34.0)$ & \\
\hline Grade 2 & $2(50.0)$ & $21(55.3)$ & $3(60.0)$ & $26(55.3)$ & $0.495^{\mathrm{a}}$ \\
\hline Grade 3 & $1(25.0)$ & $3(7.9)$ & $1(20.0)$ & $5(9.6)$ & \\
\hline
\end{tabular}

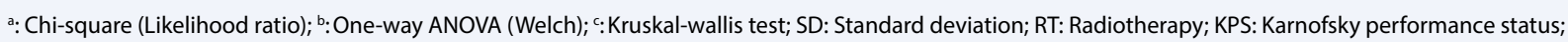
CA: Carcinoma 
Table 2 Some clinical parameters of patients according to stage groups

\begin{tabular}{lccccc} 
& Stage I $(\mathbf{n}=\mathbf{4})$ & Stage II $(\mathbf{n}=\mathbf{3 8})$ & Stage III $(\mathbf{n}=\mathbf{5})$ & Total & p \\
\hline Metastasis_time & - & $2.21 \pm 8.50$ & $5.80 \pm 6.38$ & $2.17 \pm 7.60$ & $0.040^{\mathrm{b}}$ \\
Local recurrence & - & $1.16 \pm 6.21$ & $1.60 \pm 3.58$ & $1.19 \pm 5.55$ & $0.436^{\mathrm{b}}$ \\
\hline
\end{tabular}

b: Kruskal-Wallis; SD: Standard deviation

$20.0 \%$ of Stage III patients had non-urothelial (other) histopathological type. All of Stage I patients, $63.2 \%$ of Stage II patients, $60.0 \%$ of Stage III patients had KPS $>70$. Charlson Comorbidity Criteria, all of stage I patients had over 3 score, and $57.9 \%$ of patients II patients had 2-3 score, while rest of them had over 4 score. All of Stage III patients had score 2-3.

In terms of RT doses, all of Stage I patients received 60 Gy. About $92.1 \%$ of Stage II patients had 60 Gy, only one patient $(2.7 \%)$ had 64 Gy. Half of the patients $(21$ patients) received RT alone while the other half received concomitant chemoradiotherapy with cisplatin (weekly). Six patients from Stage II (15.8\%) and one patient from Stage III (20.0\%) discontinued RT treatment.

Bone metastasis was dominant in Stage III patients. Follow-up duration mean was the highest in Stage I patients (33 month). All patients in the Stage III were died. Mortality rate was $25.0 \%$ in Stage I and $73.7 \%$ in Stage II patients.

RT and CRT treatment was well tolerated. It was seen in $4(10.5 \%)$ patients with Grade 2 diarrhea Stage II. Urinary frequency was most common in Stage II patients. In terms of late toxicity, three patients (7.9\%) had Grade 3 cystitis in Stage II and one patient (20.0\%) had Grade 3 cystitis in Stage III. One patient in Stage III, two patients in Stage II required hospitalization due to late side effects. According to difference analysis results, all differences between stage groups were not statistically significant ( $\mathrm{p}>0.05)$.

Some clinical parameters of patients according to stage groups are given in Table 2. Metastasis time was the highest in the Stage III patients and metastasis time showed significantly difference between stage groups $(\mathrm{p}<0.05)$.

Kaplan-Meier results for stage and KPS groups are given in Figures 1 and 2. Cumulative DFS was the highest in Stage II $(19.58 \pm 20.35)$ patients, followed by Stage I (13.25 \pm 8.84$)$ and Stage III (7.60 \pm 5.18$)$, respectively. Overall survival (OS) was highest in Stage I $(33 \pm 14.7)$ patients, followed by Stage II $(31.9 \pm 23)$ and Stage III (11.6 \pm 34$)$, respectively. We found that OS and DFS were statistically significant according to the stages $(p=0.08$

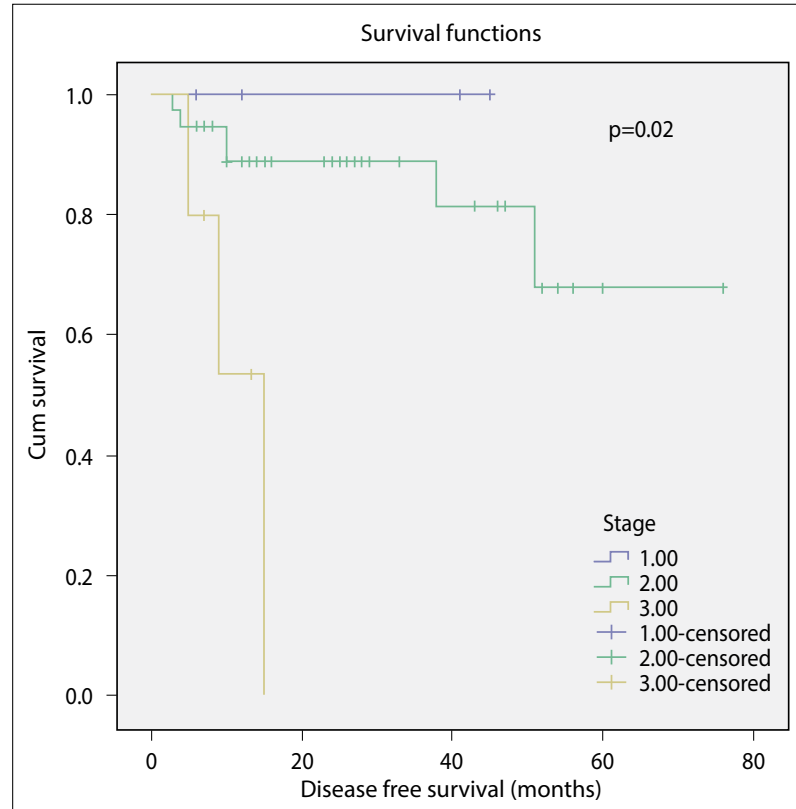

Fig. 1. Disease free survival results for stage.

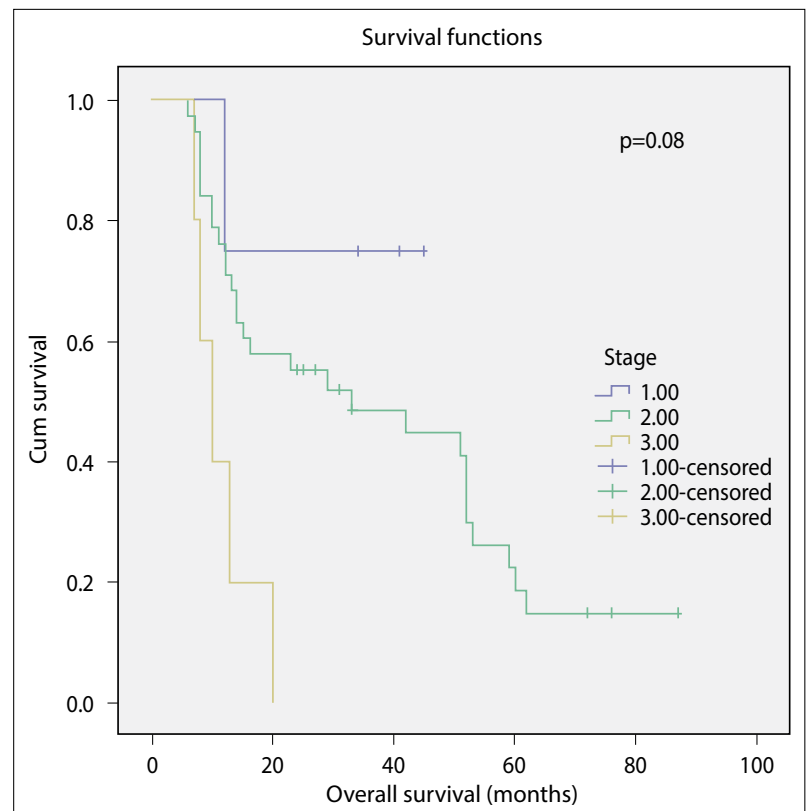

Fig. 2. Overall survival results for stage. 
and $\mathrm{p}=0.02)$. Mean DFS for KPS $>70$ group $(25.97 \pm 19.06)$ was higher than KPS $<70$ group $(2.37 \pm 1.53)$ with statistically significant difference $(\mathrm{p}<0.05)$.

\section{Discussion}

Bladder cancer is a type of cancer that is more common in advanced years of life, especially in women than in men. In men, it has 9.6 incidences and 3.2 prevalence per 100,000 people, more than women.[1] In our study, $19.2 \%$ of the sample was female and $80.8 \%$ was male. Bladder cancer is more common in older adults. The average age of diagnosis is 72 years.[1] When we look at the average age by stage, similar results were found.

Gross hematuria and painless bleeding are most important sign in bladder cancer.[7] Especially in Stage 2, hematuria and clotting hematuria were the most common symptoms in our study (68.4\% and $31.6 \%$ ).

Smoking is one of the important risk factors in bladder cancer. Studies in the literature show that smoking is one of the most important factors. [8-10] Barbosa et al.[8] reported that $17.4 \%$ of bladder cancer patients had never smoked, $46.8 \%$ had previously smoked, and $33.9 \%$ had still smoked. Jiang et al.[11] reported that smoking not only increases the risk of bladder cancer but also adversely affects stage and disease progression. On the other hand, Castelao et al.[12] reported that women who smoke have a higher risk of bladder cancer than men who smoke. In our study, $21.2 \%$ of the patients were non-smokers, $42.3 \%$ were smokers, and $36.5 \%$ had previously smoked.

KPS is an parameter used in bladder cancer and other cancer. While making the treatment decision, the general condition of the patient is evaluated with this parameter. In the study conducted by Wujanto et al.,[13] performance of patients was prognostic factor affecting survival. In our study, the survival rate was higher in patients with KPS $\geq 70$.

Charlson Comorbidity Index is use geriatric oncology patients. The patient is given points according to the additional diseases. Our patients were generally found to be 3 points or more.

In many studies on elderly bladder cancer, RT dose was applied over $60 \mathrm{~Gy}$. Median $58.6 \mathrm{~Gy}$ (range 54-62.8) was used in the study of Lee et al.,[14] The median 64.8 Gy was used in the study of Hsieh et al.(15) and 60-60 Gy received in the study of Korpics et al .(16) Similar to the above studies, we applied median $60 \mathrm{~Gy}$ and $64 \mathrm{~Gy}$ to pelvic area and bladder. We did not find statistical difference between 60 and $64 \mathrm{~Gy}$ when compared by stages. In our study, 26 patients received CRT, while 21 patients received RT only. Patients who break the treatment were generally Stage 2 (six patients) and CRT used patients. CRT and RT was well tolerated all patients. Diarrhea, urinary frequency, and hematologic side effects were most common in Stage II patients. In the late period, three patients (7.9\%) had Grade 3 cystitis. Our side effect results were similar to other studies.[14-17]

Metastasis was most common in the liver after treatment. Follow-up time was at least 11 months with Stage III. In other stages, the follow-up period was approximately 30 months.

Stage of bladder cancer is an important factor that affects both the course of the disease and survival rate. Studies have been conducted in the literature regarding the stage and course of the disease and different results have been reported.[18-20]

In our study, clinical, treatment, toxicity, demographic parameters did not differ significantly according to the stages. OS and DFS are significantly difference between stage groups $(\mathrm{p}=0.08$ and $\mathrm{p}=0.02)$. DFS and OS were observed at the lowest Stage III. The reason for this is that patients are lost due to additional diseases or they are receiving alone RT. DFS and OS were found at the highest Stage II. Because, almost all of these patients received CRT.

A limitation of our study was almost all patients Stage II. According to the stages, the number of patients was not homogeneously distributed. It was not clear whether the cause of death was due to the additional disease. Bladder cancer is mostly diagnosed in older patients; a comprehensive assessment is required when deciding on the options for curative treatment.

\section{Conclusion}

According to the results of the study, RT alone or CRT can be safely performed at all stages in patients over 70 years of age. Longer life expectancy and "KPS over 70" older bladder cancer patients, RT and CRT treatment should be taking into consideration. When making treatment decision, performance status most important than the patients chronological age and stage.

Peer-review: Externally peer-reviewed.

Conflict of Interest: The authors have no conflicts of interest to declare.

Ethics Committee Approval: The study was approved by the University of Health Science, Istanbul Training and Research Hospital Clinical Research Ethics Committee (No: 2019-1859, Date: 14/06/2019). 
Financial Support: The authors declared that this study has received no financial support.

Authorship contributions: Concept - B.İ.; Design - B.İ., Ö.M.; Supervision - Ö.M.; Funding - B.İ.; Materials - B.İ., Ö.M.; Data collection and/or processing - B.İ.; Data analysis and/or interpretation - B.I., Ö.M.; Literature search Ö.M.; Writing - B.İ.; Critical review - B.İ.

\section{References}

1. Bray F, Ferlay J, Soerjomataram I, Siegel R, Torre L, Jemal A. Global Cancer Statistics 2018: GLOBOCAN estimates of incidence and mortality worldwide for 36 cancers in 185 countries. CA Cancer J Clin 2018;68(6):394-424.

2. Lee MS, Lee J, Kim JH, Kim WT, Kim WJ, Ahn H, et al. Overexpression of caldesmon is associated with tumor progression in patients with primary non-muscle-invasive bladder cancer. Oncotarget 2015;6(37):4037084.

3. Mak RH, Hunt D, Shipley WU, Efstathiou JA, Tester WJ, Hagan MP, et al. Long-term outcomes in patients with muscle-invasive bladder cancer after selective bladder-preserving combined-modality therapy: a pooled analysis of radiation therapy oncology group protocols 8802, 8903, 9506, 9706, 9906, 0233. J Clin Oncol 2014;32(34):3801-9.

4. Lin HY, Ye H, Krauss DJ. Muscle invasive bladder cancer survival after radical cystectomy or definitive chemoradiation: a national cancer database matched pair analysis. Int J Radiat Oncol Biol Phys 2017;99(2):252.

5. Sundararajan V, Henderson T, Perry C, Muggivan A, Quan H, Ghali WA. New ICD-10 version of the charlson comorbidity index predicted in-hospital mortality. J Clin Epidemiol 2004;57(12):1288-94.

6. US Department of Health and Human Services. Common terminology criteria for adverse events (CTCAE). Available at: http://www.evs.nci.nih.gov/ftp1/CTCAE/ CTCAE_4.03_2010-06-14_QuickReference_8.5x11. pdf. Accessed Jun 14, 2010.

7. Davis R, Jones JS, Barocas DA, Castle EP, Lang EK, Leveillee RJ, et al. American Urological Association diagnosis, evaluation and follow-up of asymptomatic microhematuria $(\mathrm{AMH})$ in adults: AUA guideline. J Urol 2012;188(6):2473-81.

8. Barbosa AL, Vermeulen SH, Aben KK, Grotenhuis AJ, Vrieling A, Kiemeney LA. Smoking intensity and bladder cancer aggressiveness at diagnosis. PLoS One 2018;13(3):e0194039.

9. Osch F, Jochems J, Schooten F, Bryan T, Zeegers M. Quantified relations between exposure to tobacco smoking and bladder cancer risk: a meta-analysis of 89 observational studies. Int J Epidemiol 2016;45(3):85770 .

10. Alberg AJ, Hébert JR. Cigarette smoking and bladder cancer: a new twist in an old saga? J Natl Cancer Inst 2009;102(2):1525-6.

11. Jiang X, Castelao JE, Yuan JM, Stern MC, Conti DV, Cortessis VK, et al. Cigarette smoking and subtypes of bladder cancer. Int J Cancer 2012;130(4):896-901.

12. Castelao J, Yuan JM, Skipper P, Tannenbaum SR, Gago-Dominguez M, Crowder JS, et al. Gender-and smoking-related bladder cancer risk. J Natl Cancer Inst 2001;93(7):538-45.

13. Wujanto C, Tey J, Chia D, Ho F, Ooi KH, Wong AS, et al. Radical radiotherapy in older patients with muscle invasive bladder cancer. J Geriatr Oncolo 2019;10(2):292-7.

14. Lee YT, Wu YT, Yen CC, Chang MH, Chang YH, Chung HJ, et al. Concurrent chemoradiotherapy in elderly patients with muscle-invasive bladder cancer: a single-center experience. J Cancer Res Pract 2016;3(3):73-6.

15. Hsieh CH, Chung SD, Chan PH, Lai SK, Chang HC, Hsiao $\mathrm{CH}$, et al. Intensity modulated radiotherapy for elderly bladder cancer patients. Radiat Oncol 2011;6(1):75.

16. Korpics MC, Block AM, Martin B, Hentz C, Gaynor ER, Henry E, et al. Concurrent chemotherapy is associated with improved survival in elderly patients with bladder cancer undergoing radiotherapy. Cancer 2017;123(18):3524-31.

17. Turgeon GA, Souhami L, Cury FL, Faria SL, Duclos M, Sturgeon J, et al. Hypofractionated intensity modulated radiation therapy in combined modality treatment for bladder preservation in elderly patients with invasive bladder cancer. Int J Radiat Oncol Biol Phys 2014;88(2):326-31.

18. Guo CC, Czerniak B. Bladder cancer in the genomic era. Arch Pathol Lab Med 2019;143(6):695-704.

19. Zhu CZ, Ting HN, Ng KH, Ong TA. A review on the accuracy of bladder cancer detection methods. J Cancer 2019;10(17):4038-44.

20. Kim WJ. Changing landscape of diagnosis and treatment of bladder cancer. Investig Clin Urol 2016;57(1):1-3. 